\title{
Size Dictates in the Treatment of Papillary Thyroid Carcinoma
}

\author{
Islam MA ${ }^{1 *}$, Mohammed T2 ${ }^{2}$ Mamoon $\mathrm{TB}^{3}$, Chowdhury $\mathrm{NH}^{4}$, Khan $\mathrm{SR}^{5}$, Milki FU ${ }^{6}$ and Rahman ASML \\ ${ }^{1}$ Professor and Head, Otolaryngology-Head \& Neck Surgery, Bangladesh Medical College Hospital, Bangladesh \\ ${ }^{2}$ Assistant Registrar, ENT, Bangladesh Medical College Hospital, Bangladesh \\ ${ }^{3}$ Assistant Registrar, ENT, Bangladesh Medical College Hospital, Bangladesh \\ ${ }^{4}$ Assistant Professor, ENT, Bangladesh Medical College Hospital, Bangladesh \\ ${ }^{5}$ Assistant registrar, ENT, National Institute of ENT, Bangladesh. \\ ${ }^{6}$ Consultant ENT, Bangladesh Medical College Hospital, Bangladesh
}

${ }^{7}$ Resident Surgeon, Bangladesh Medical College Hospital, Bangladesh

*Corresponding author: Ashraful Islam, Professor and Head Department of Otolaryngology-Head \& NeckSurgery, Bangladesh Medical College, Dhaka, Bangladesh.
Received Date: August 11, 2020

Published Date: August 14, 2020

\section{Abstract}

Background \& objectives: Papillary thyroid cancer (PTC) is the most prevalent histologic subtype of thyroid cancer accounting for more than $80 \%$ of all cases and size of the thyroid nodule in PTC is considered the determinant factor in thyroid surgery i.e. hemithyroidectomy or total thyroidectomy. A single size threshold of $4 \mathrm{~cm}$ maximized prognostic discrimination with tumors size $>4 \mathrm{~cm}$ associated with a five times higher risk of recurrence than those $\leq 4 \mathrm{~cm}$. The present study aimed to determine an effective treatment strategy for patients with small unilateral papillary thyroid carcinoma in a low risk group below tumor size $\leq 4 \mathrm{~cm}$.

Material and methods: A prospective study was carried out on 700 patients who were diagnosed as papillary thyroid carcinoma by preoperative FNAC or postoperative histopathology. The age of the patients' was ranged between 15 to 45 years. The criteria were: tumor $\leq 4 \mathrm{~cm}$, unilateral involvement, cytological non-aggressive subtype, absence of lymph node involvement and extra thyroidal extension on ultrasonography and absence of clinical distant metastases. The study was conducted in tertiary care hospital in Bangladesh from 2004 to 2019.

Results: 700 patients were included in the study, 667 patients (95.3\%) did not show any recurrence of disease. 33 patients (4.7\%) came with locoregional recurrence of disease in clinical and USG findings without any distant metastasis. Maximum patients were between the ages 31-40 year followed by 21-30 year. Female was outnumber male in the ratio 2.5:1 $\mathrm{cm}$.

Conclusion: This study can lead to a result that hemi thyroidectomy is now-a-days a better surgical option for PTC even up to tumor size of $\leq 4$

Keywords: Thyroid papillary carcinoma; Hemi-thyroidectomy; Size; Recurrence

\section{Introduction}

The incidence of thyroid cancer has been gradually increasing in the whole world over the past 20 to 30 years [1-4]. It is documented that papillary thyroid cancer (PTC) represents more than $90 \%$ amongst all thyroid cancer variants and are practically emerging in the vast majority of cases in every year. The treatment for papillary thyroid cancer is surgical resection and the prognosis is excellent as the disease is biologically innocent in nature.

There has been a long debate in regard to extent of surgery i.e. total thyroidectomy, near-total thyroidectomy, lobectomy and hemi-thyroidectomy for a small size tumor $\leq 4 \mathrm{~cm}$ unilateral 
papillary thyroid cancer (PTC) without any preoperative evidence of extrathyroid extension and without nodal involvement [5-8]. Even the correct approach to treat low-risk intra thyroidal papillary thyroid carcinoma (PTC) is still controversial. The traditional paradigm of treating all patients with thyroid cancer with total thyroidectomy, radioactive iodine (RAI), and suppressive thyroid hormone therapy is no longer suitable today. Rather, patients with thyroid cancer should receive treatment depending on the size of the tumor, nodal involvement and age of the patient.

Hemi-thyroidectomy in the treatment of low-risk tumors has expanded widely on the basis of active surveillance. Previously, hemi thyroidectomy was only indicated for unifocal tumors $<1 \mathrm{~cm}$ in size without preoperative evidence of extra thyroid extension or lymph node metastases (N0). More recent evidence however, suggests that hemi thyroidectomy can be safely performed in patients even with larger tumors. A sentinel study published by Bilimoria et al [9] based on the NCDB database documented that recurrence was slightly but statistically higher (9.8\% vs. $7.7 \%)$ and survival was slightly lower (97.1\% vs. $98.4 \%$ ) in lobectomy patients vs. bilateral resection. However, it is evident in a publication from Memorial Sloan Kettering Cancer Center [10] that there is no difference between lobectomy to near-total/total thyroidectomy in respect to survival of T1-2 N0 PTC patients.

The controversy has been come forward to reviewing the two recent publications in the treatment of PTC even as large as $4 \mathrm{~cm}$ $[11,12]$. The Japanese study reviewed over 1,000 patients who underwent lobectomy for tumors up to $4 \mathrm{~cm}$ in size, with a followup period of 17.6 years (without addition of RAI), in the absence of clinically positive lymph nodes or extra thyroidal extension where no patient died under 45 years of age. The American study re-analyzed 61,775 patients from the NCDB, and overall survival was similar in patients undergoing total thyroidectomy versus lobectomy for tumors $1-4 \mathrm{~cm}$ in size.

PTC, although the label of cancer is applied to these small tumors, with rare exception, they are indolent, even though the spread to lymph nodes occurs in about 30\% $[13,14]$ these metastasis are usually quite small and recurrence is seldom seen.

\section{Objective}

The purpose of the present study was:

1. To determine an effective treatment strategy for patients with small unilateral papillary thyroid in a low risk group below tumor size $\leq 4 \mathrm{~cm}$

\section{Methods}

Study design: prospective study.

Study sample: 700 patients.

Sampling technique: Simple non-random sampling.

Study period: 30 years (1989-2019).

\section{Study places}

1. Bangladesh Medical College Hospital.

2. Popular Medical College Hospital.

3. Combined Military Hospital, Dhaka.

4. Padma General Hospital.

\section{Inclusion criteria}

1. Tumor size $\leq 4 \mathrm{~cm}$.

2. Unilateral involvement

3. Diagnosed as papillary thyroid carcinoma by preoperative FNAC or postoperative histopathology.

4. Cytological non-aggressive subtype.

5. Absence of lymph node involvement and extra thyroidal extension on ultrasonography.

\section{Absence of clinical distant metastases}

\section{Exclusion criteria}

1. Patients unfit for surgeries.

2. Patients not giving consent.

6. $\quad$ Procedure

The selected patients and their guardians were thoroughly counseled regarding nature of disease, prognosis, surgical options, advantages \& disadvantages of each surgical modalities and importance of regular follow-up.

All surgeries were done under general anesthesia. Transverse skin crease incision was being made. Skin \& sub-platysmal flap were elevated. Affected lobe of thyroid was mobilized. Recurrent laryngeal nerve and parathyroid glands were identified \& preserved in each case. After proper hemostasis wound closed in layers keeping 01 drain in situ. During anesthetic recovery, vocal cord movement was checked in every case.

Following surgery, patients were kept in close observation in post-operative ward. Drain was usually removed on 2nd or 3rd POD depending on amount \& color of fluid in drain tube. After removal of drain patients were discharged from hospital and advised to come with histopathology report on 7th POD.

Follow-up schedule

1) After reviewing histopathology report patients were advised for follow-up monthly for first 03 months then every 03 months for next 06 months and yearly for the rest of their life.

2) All patients had followed up by a median period of 25 months (6 months to 166 months).

3) During each visit they were advised to bring the test 
reports of TSH, FT4, Thyroglobulin and patients were clinically examined.

\section{Result}

In our study total 700 patients were included. Among them 500 (71.4 \%) were female \& $200(28.6 \%)$ were male shown in (Table 1). $310(44.3 \%)$ patients were aged between 31 to 40 years. The youngest patient was 17 years old and the oldest being 45 years presented in (Table 2). Preoperative USG of each patient was done. All of them were unilateral involvement with tumor size $\geq 4 \mathrm{~cm}$. 657 (93.9\%) patients were diagnosed as papillary thyroid carcinoma by pre-operative FNAC. Rests of the patients were initially diagnosed as benign tumor of thyroid. After surgery histopathology revealed papillary carcinoma (Table 3).

All patients had undergone hemi thyroidectomy without Radioactive Iodine Ablation and followed up by a median period of 25 months (6 months to 166 months).

Table 1: Sex Distribution of study population $(n=700)$.

\begin{tabular}{|c|c|c|}
\hline Sex distribution & Number of patients & \% \\
\hline Female & 500 & 71.4 \\
\hline Male & 200 & 28.6 \\
\hline
\end{tabular}

Table 2: Age distribution of study population $(n=700)$.

\begin{tabular}{|c|c|c|}
\hline Age (Years) & Number of patients & \% \\
\hline $11-20$ & 37 & 36.8 \\
\hline $21-30$ & 258 & 44.3 \\
\hline $31-40$ & 310 & 13.6 \\
\hline $41-50$ & 95 & 100 \\
\hline
\end{tabular}

Table 3: Preoperative diagnosis by FNAC $(n=700)$.

\begin{tabular}{|c|c|c|}
\hline Histo-diagnosis & Number of patients & \% \\
\hline Papillary thyroid carcinoma & 657 & 93.9 \\
\hline Nodular goiter & 43 & 6.1 \\
\hline
\end{tabular}

Table 4: Result following hemithyroidectomy on follow-up ( $n=700)$.

\begin{tabular}{|c|c|c|}
\hline Result & Number of patients & $\%$ \\
\hline No recurrence & 667 & 95.3 \\
\hline Recurrence & 33 & 4.7 \\
\hline
\end{tabular}

Table 5: Sex distribution among recurrent cases $n=33(700)$

\begin{tabular}{|c|c|c|}
\hline Sex distribution & Number & $\%$ \\
\hline Female & $21(500)$ & 4.2 \\
\hline Male & $12(200)$ & 6 \\
\hline
\end{tabular}

Table 6: Age distribution of recurrent cases $n=33(700)$.

\begin{tabular}{|c|c|c|}
\hline Age (Years) & Number & $\%$ \\
\hline $11-20$ & $1(37)$ & 2.7 \\
\hline
\end{tabular}




\begin{tabular}{|l|c|c|}
\hline $21-30$ & $12(258)$ & 4.7 \\
\hline $31-40$ & $16(310)$ & 5.2 \\
\hline $41-50$ & $4(95)$ & 4.2 \\
\hline
\end{tabular}

\section{Discussion}

It is evident that thyroid cancer rates are on the rise and is considered the most prevalent endocrine malignancy all over the world; and histologically mostly the papillary thyroid carcinoma $[15,16]$. Till to date, the treatment options remain in the dilemma to the extent of surgery in low risk PTC. Thyroid surgery either total thyroidectomy or hemithyroidectomy should be performed by high-volume surgeons ( $>25$ thyroid surgeries yearly) to avoid surgical complications [17-19]. In our series it is experienced that hemithyroidectomy is appropriate for low-risk thyroid cancer to prevent recurrence. It is more than ever essential to explain the merits/demerits of the modalities of surgery i.e. total thyroidectomy versus hemithyroidectomy in presence of the patients/attendants. So they can be well aware themselves fully in a conversation around what is the best modalities of surgery. In our study, each of the patients \& patients' attendants were thoroughly counseled regarding nature of disease, prognosis, surgical options, advantages $\&$ disadvantages of each options and importance of regular followup.

It has been observed in the published literature so far that patients with thyroid cancer $>1 \mathrm{~cm}$ and $\leq 4 \mathrm{~cm}$ without extrathyroidal extension, without clinical evidence of any lymph node metastases, the initial surgical procedure can be either a near-total/total thyroidectomy or a lobectomy [20-23]. The higher surgical risks e.g. transient or permanent post-surgical hypo parathyroidism, recurrent laryngeal nerve injury unilateral or bilateral, hematoma formation, infection is documented in total or near total thyroidectomy especially in the hands of inexperienced surgeons. These patients need lifelong thyroid hormone replacement and postoperative radioiodine ablation (RAI) [24-25]. A study by Popadich et al found that the addition of routine central lymph node dissection with thyroid surgery in patients in cN0 papillary thyroid carcinoma reduced the need for reoperation in the central compartment and was associated with lower postoperative thyroglobulin levels $[26,27]$.

In this study, hemithyroidectomy was carried out in all 700 patients and no patient had developed any perioperative or postoperative surgical complications. The only drawback experienced after surgery was regarding their biochemical followup; therefore, the follow-up mostly relied on clinical assessment and ultrasonography findings. In this series, locoregional recurrence was found in only 33 cases (4.7\%) who needed second surgery which is also shown in other study $[28,29]$. There was no evidence of distant metastasis noted in those recurrent patients on our follow up. A follow-up for 6 years in low risk PTC hemithyroidectomy patients done by Siassakos et al [26] and identified no recurrence, metastases or mortalities. The authors concluded that in this sample of patients with PTC, no further surgical or radiotherapeutic intervention was warranted $[26,28]$. Another similar study showed in 281 PTC patients where only 3.9\% developed locoregional recurrence, and one patient presented metastasis in the lung [29]. In this study, at the time of final follow-up with a median of 7 years, $95.3 \%$ showed disease free survival and $4.7 \%$ had recurrence who underwent second surgery which correlates almost similar result cited in the above observation.

Total thyroidectomy with RAI and lifelong thyroid hormone replacement had increased chance of developing complications. On the other hand, hemithyroidectomy does not need RAI and hormonal replacement thus reduce the cost/extra burden in the developed and developing country. Though further large scale study should require to determine the optimal treatment option for unilateral thyroid tumor size $\leq 4 \mathrm{~cm}$ in low risk PTC, but this study can lead to a result that hemithyroidectoy is at present can be considered as a better surgical modality up to tumor size of $\leq 4 \mathrm{~cm}$. In this study locoregional recurrence was found in only $4.7 \%$ cases without any evidence of distant metastases. It is found in our series that recurrences were more frequent $5.2 \%$ between the ages of 31 to 40 year followed by ages 41 to 50 year. It is probably because of the fact that the patient turn over weas more in the 31-40 years of age but most of the literature showed the high recurrence rate in the elderly ages [29-32]. Follow up by serial USG is one of the most important parameters in hemi thyroidectomy patients of PTC.

\section{Conclusion}

A papillary thyroid carcinoma equal or less than $4 \mathrm{~cm}$, confined to unilateral thyroid lobe with no lymph node involvement or extra thyroidal extension and in the absence of distant metastases, hemithyroidectomy is the treatment of choice. It is cost effective and does not need postoperative hormone therapy. Surgical options and importance of postoperative follow up details should be discussed clearly to the patients prior to surgical intervention.

\section{Acknowledgement}

None.

\section{Conflict of Interest}

No conflict of interest.

\section{References}

1. Davies L, Welch HG (2014) Current thyroid cancer trends in the United States. JAMA Otolaryngol Head Neck Surg 140: 317-322.

2. Davies L, Morris LG, Haymart M, Chen AY, Goldenberg D, et al. (2015) American Association of Clinical Endocrinologists and American College 
of Endocrinology disease state clinical review: the increasing incidence of thyroid cancer. Endocr Pract 21: 686-696.

3. Vaccarella S, Dal Maso L, Laversanne M, Bray F, Plummer M, et al. (2015) The impact of diagnostic changes on the rise in thyroid cancer incidence: a population-based study in selected high-resource countries. Thyroid 25: $1127-1136$

4. Vaccarella S, Franceschi S, Bray F, Wild CP, Plummer M, et al. (2016) Worldwide thyroid-cancer epidemic? The increasing impact of overdiagnosis. N Engl J Med 375: 614-617.

5. Buckwalter JA and Thomas CG (1972) Selection of surgical treatment for well differentiated thyroid carcinomas. Ann Surg 176: 565-568

6. Christensen SB, Ljungberg O, Tibblin S (1983) Surgical treatment of thyroid carcinoma in a defined population: 1960 to 1979. Evaluation of the results after a conservative surgical approach. The American Journal of Surgery 146(3): 349-354.

7. Demeure MJ, Clark OH (1990) Surgery in the treatment of thyroid cancer. Endocrinol Metab. Clin North Am 19: 663-683.

8. Friedman M and Pacella BL (1990) Total versus subtotal thyroidectomy: arguments, approaches and recommendations. Otolaryngol Clin North Am 23: 413-427.

9. Bilimoria KY, Bentrem DJ, Ko CY (2007) Extent of surgery affects surviva for papillary thyroid cancer. Ann Surg 246: 375-381.

10. Nixon IJ, Ganly I, Patel SG (2012) Thyroid lobectomy for treatment of well differentiated intrathyroid malignancy. Surgery 151: 571-590.

11. Matsuzu K, Sugino K, Masudo K (2014) Thyroid lobectomy for papillary thyroid cancer: long-term followup study of 1,088 cases. World J Surg 38: 68-79.

12. Adam MA, Pura J, Gu L (2014) Extent of surgery for papillary thyroid cancer is not associated with survival: an analysis of 61,775 patients. Ann Surg 260: 601-605.

13. Hay ID, Hutchinson ME, Gonzalez-Losada T (2008) Papillary thyroid microcarcinoma: a study of 900 cases observed in a 60-year period. Surgery 144: 980-987.

14. Chow SM, Law SC, Chan JK (2003) Papillary microcarcinoma of the thyroid-Prognostic significance of lymph node metastasis and multifocality. Cancer 98: 31-40.

15. Geron Y, Benbassat C, Shteinshneider M, Koren S, Markus E, et al. (2019) Long-Term Outcome after Hemithyroidectomy for Papillary Thyroid Cancer: A Comparative Study and Review of the Literature. Cancers (Basel) 11(1): 26.

16. Jatin PS (2015) Thyroid Carcinoma: Epidemiology, Histology, and Diagnosis. Clin Adv Hematol Oncol 13(4 Suppl 4): 3-6.

17. Adam MA, Thomas S, Youngwirth L, Hyslop T, Reed SD, et al. (2017) Is there a minimum number of thyroidectomies a surgeon should perform to optimize patient outcomes? Ann Surg 265: 402-407.

18. Al-Qurayshi Z, Robins R, Hauch A, Randolph GW, Kandil E (2016) Association of surgeon volume with outcomes and cost savings following thyroidectomy: a national forecast. JAMA Otolaryngol Head Neck Surg 142: 32-39.

19. Youngwirth LM, Adam MA, Scheri RP, Roman SA, Sosa JA (2016) Patients treated at low-volume centers have higher rates of incomplete resection and compromised outcomes: analysis of 31,129 patients with papillary thyroid cancer. Ann Surg Oncol 23: 403-409.

20. Padovani RP, Robenshtok E, Brokhin M, Tuttle RM (2012) Even without additional therapy, serum thyroglobulin concentrations often decline for years after total thyroidectomy and radioactive remnant ablation in patients with differentiated thyroid cancer. Thyroid 22: 778-783.

21. Shah JP, Loree TR, Dharker D, Strong EW (1993) Lobectomy versus total thyroidectomy for differentiated carcinoma of the thyroid: A matchedpair analysis. Am J Surg 166: 331-335.

22. Barney BM, Hitchcock YJ, Sharma P, Shrieve DC, Tward JD (2011) Overall and cause-specific survival for patients undergoing lobectomy, near-total, or total thyroidectomy for differentiated thyroid cancer. Head Neck 33: 645-649.

23. Kim MJ, Lee MC, Lee GH, Choi HS, Cho SW, et al. (2017) Extent of surgery did not affect recurrence during 7-years follow-up in papillary thyroid cancer sized 1-4cm: Preliminary results. Clin Endocrinol 87: 80-86.

24. Ji YB, Song CM, Kim D, Sung ES, Lee DW, et al. (2019) Efficacy of hemithyroidectomy in papillary thyroid carcinoma with minimal extrathyroidal extension. Eur Arch Otorhinolaryngol 276: 3435-3442.

25. Papaleontiou M, Hughes DT, Guo C, Banerjee M, Haymart MR (2017) Population-based assessment of complications following surgery for thyroid cancer. J Clin Endocrinol Metab 102: 2543-2551.

26. Siassakos D, Gourgiotis S, Moustafellos P, Dimopoulos N, Hadjiyannakis E (2008) Thyroid microcarcinoma during thyroidectomy. Singapore Med J 49: 23-25.

27. Baudin E, Travagli JP, Ropers J (1998) Microcarcinoma of the thyroid gland: the Gustave-Roussy Institute experience. Cancer 83: 553-559.

28. Pacini F, Elisei R, Capezzone M, Miccoli P, Molinaro E, et al. (2001) Contralateral papillary thyroid cancer is frequent at completion thyroidectomy with no difference in low- and high-risk patients. Thyroid 11: 877-881.

29. Mendelsohn AH, Elashoff DA, Abemayor E, St John MA (2010) Surgery for papillary thyroid carcinoma: Is lobectomy enough? Arch. Otolaryngol. Arch Otolaryngol Head Neck Surg 136: 1055-1061.

30. Tuttle RM, Tala H, Shah J (2010) Estimating risk of recurrence in differentiated thyroid cancer after total thyroidectomy and radioactive iodine remnant ablation: using response to therapy variables to modify the initial risk estimates predicted by the new American Thyroid Association staging system. Thyroid 20: 1341-1349.

31. EA, King TA, Bolton JS, Fuhrman GM (2002) A comparison of total thyroidectomy and lobectomy in the treatment of dominant thyroid nodules. Am Surg 68: 678-682.

32. Roti E, degli Uberti EC, Bondanelli M (2008) Thyroid papillary microcarcinoma: a descriptive and meta-analysis study. Eur J Endocrinol 159: 